\title{
PENGARUH KEPEMIMPINAN TERHADAP KINERJA KARYAWAN BADAN PENGAWAS PEMILU KOTA ADMINISTRASI JAKARTA SELATAN
}

\author{
Oleh: Moh. Khoiri*, Nurul Rahma Oktavia*
}

\begin{abstract}
ABSTRAK
Tujuan dari penelitian ini adalah untuk mengetahui bagaimana kepemimpinan dan kinerja karyawan bawaslu kota administrasi jakarta selatan, serta untuk mengetahui apakah terdapat pengaruh kepemimpinan terhadap kinerja karyawan bawaslu kota administrasi jakarta selatan. Metode penelitian yang digunakan dalam penelitian ini adalah Deskriptif Asosiatif dengan pendekatan kuantitatif, yaitu dengan mendeskripsikan keadaan responden serta deskripsi variabel penelitian dalam tabel frekuensi dan presentase dari hasil penyebaran kuesioner tersebut dengan melalui prosedur analisis data. Populasi dalam penelitian ini sebanyak 96 orang dan jumlah sampel sebanyak 96 responden dengan menggunakan sampel jenuh. Teknik analisis data menggunakan uji validitas, uji reliabilitas, regresi linear sederhana, koefisien korelasi, koefisien determinasi dan uji hipotesis (uji t). Hasil penelitian menunjukan bahwa persepsi karyawan untuk variabel kepemimpinan dan kinerja karyawan saat ini sudah baik. Nilai koefisien regresi variabel kepemimpinan terhadap kinerja karyawan adalah sebesar 0,484 . Hal ini berarti jika kepemimpinan naik 1 satuan maka akan meningkatkan kinerja sebesar 0,484. Korelasi dibuktikan dengan rxy sebesar 0,468 yang artinya terdapat hubungan positif yang sedang antara kepemimpinan dengan kinerja karyawan dan koefisien determinasi sebesar $21,90 \%$, sementara sisanya sebesar $78,1 \%$ dipengaruhi oleh faktor lain yang tidak diteliti. Hasil uji hipotesis diperoleh nilai thitung $(4,934)>t_{\text {tabel }}(1,990)$, dengan taraf $5 \%$, hal ini menunjukan bahwa terdapat pengaruh yang positif dan signifikan antara variabel kepemimpinan terhadap kinerja karyawan Bawaslu Kota Administrasi Jakarta Selatan
\end{abstract}

Kata Kunci: Kepemimpinan, Kinerja Karyawan, Badan Pengawas Pemilu.

\section{ABSTRACT}

The purpose of this study was to determine how the leadership and performance of South Jakarta city administration bawaslu employees, as well as to find out whether there is an influence of leadership on the performance of South Jakarta city administration bawaslu employees. The research method used in this research is Associative Descriptive with a quantitative approach, namely by describing the condition of the respondent as well as a description of the research variables in the frequency table and the percentage of the results of the distribution of the questionnaire through data analysis procedures. The population in this study were 96 people and the number of samples was 96 respondents using a saturated sample. Data analysis techniques using validity test, reliability test, simple linear regression, correlation coefficient, coefficient of determination and hypothesis testing ( $t$ test). The results showed that employee perceptions for leadership variables and current employee performance were good. The regression coefficient value of the leadership variable on employee performance is $\mathbf{0 . 4 8 4}$. This means that if leadership increases by 1 unit it will

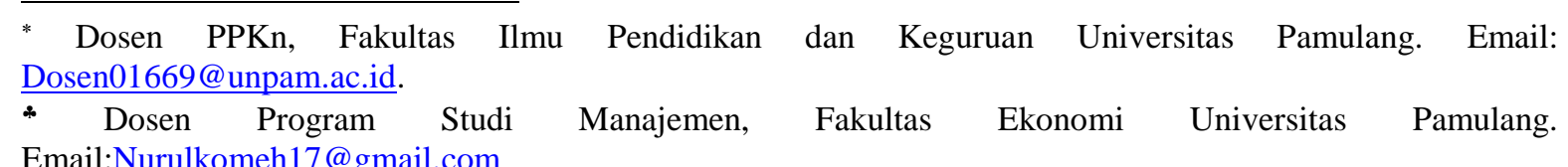


increase performance by 0.484 . Correlation is evidenced by a proxy of 0.468 , which means there is a moderate positive relationship between leadership and employee performance and a coefficient of determination of $\mathbf{2 1 . 9 0 \% , ~ w h i l e ~ t h e ~ r e m a i n i n g ~} \mathbf{7 8 . 1 \%}$ is influenced by other factors not examined. Hypothesis test results obtained tcount (4.934)> t table (1.990), with a level of 5\%, this shows that there is a positive and significant influence between leadership variables on the performance of employees of Bawaslu South Jakarta City Administration

Keywords: Leadership, Employee Performance, The Election Supervisory Board.

\section{PENDAHULUAN}

\section{A. Latar Belakang Masalah}

Karyawan ( sumber daya manusia /

SDM ) merupakan sumber daya

yang sangat penting dalam

lembaga. Karna sebagai salah satu

elemen dalam lembaga,

manajemen SDM tidak dapat di

pisahkan dari bidang manajemen

lainnya untuk mencapai tujuan

lembaga. Dan dalam lembaga

sumber daya manusia merupakan elemen paling strategik, harus kita akui dan diterima oleh manajemen.

Agar tercapai tujuan lembaga, lembaga tersebut harus mempunyai SDM yang berkualitas serta memiliki kemampuan pengelolaan yang baik dan tepat terhadap kinerja karyawannya agar sesuai dengan tujuan yang telah ditetapkan lembaga. Agar pengelolaan tersebut dapat berjalan sesuai dengan tujuan organisasi, maka upaya yang dilakukan salah satunya yakni memiliki pemimpin yang baik dalam menjalankan satu sistem kepemimpinan yang dapat berperan dalam meningkatkan kualitas sumber daya manusia khususnya bagaimana kinerja karyawan.

Saat ini permasalahan utama yang menjadi kendala dalam sebuah lembaga ialah sulitnya untuk dapat membangun sumber daya manusia (SDM) yang hebat, yang dapat menjadi pondasi kuat bagi organisasi. Faktor sulitnya memiliki sumber daya manusia yang hebat ini tak terlepas pula karena minimnya jiwa kepemimpinan (Leadership) yang di miliki oleh para pemimpin (Leader) di setiap divisi-divisi terkait di dalam sebuah lembaga.

Oleh karena itu di dalam sebuah lembaga seorang pemimpin (Leader) mempunyai peran yang sangat penting dan tanggung jawab penuh. dalam keberlangsungan lembaga tersebut. lembaga dapat dikatakan gagal ataupun berhasil dalam mencapai tujuannya terletak 
pada peranan seorang pemimpin (Leader).

\section{Setiap pemimpin (Leader)}

dalam menentukan gaya kepemimpinannya harus mampu menyesuaikan diri dengan kondisi lingkungan yang sedang terjadi. Dengan karakter yang dimiliki, maka setiap pemimpin (Leader) cenderung memiliki gaya tersendiri dalam memimpin lembaganya. Empat (4) macam gaya kepemimpinan Menurut Tohardi dikutip oleh Edy Sutrisno (2010:242) dalam Jurnal Adad Danuarta (2014) menyatakan bahwa gaya kepemimpinan diantaranya, gaya persuasif yaitu memimpin dengan cara pendekatan secara maksimal, gaya refresif yaitu memimpin dengan cara memberikan tekanan (Pressure), gaya partisipatif yaitu dengan memberikan kesempatan kepada bawahan agar lebih aktif dan kreatif, gaya inovatif merupakan pemimpin yang selalu berusaha dengan keras untuk menciptakan pembaruan-pembaruan dalam segala bidang.

$$
\text { Suatu organisasi }
$$
membutuhkan pemimpin (Leader) yang efektif serta dapat mempengaruhi perilaku karyawannya, agar mengikuti seluruh arahan yang diberikan. Menurut Miftah Thoha (2010:49) Dalam Jurnal Adad Danuarta (2014) mengemukakan bahwa gaya kepemimpinan merupakan norma perilaku yang digunakan oleh seseorang pada saat orang tersebut mencoba mempengaruhi perilaku orang lain atau bawahan.

Bersangkutan pula dengan Bawaslu Kota AdministrasiJakarta Selatan yang saat ini sedang berkembang maka di butuhkan pula pemimpin (Leader) untuk menggerakkan roda lembaga, agar lembaga dapat berjalan dengan baik sesuai dengan visi dan misi yang dimilikinya.

Kepemimpinan di Bawaslu Kota Administrasi Jakarta Selatan masih terus dalam tahap evaluasi. Berhubung dengan semakin dekatnya masa pemilihan umum sehingga membutuhkan pemimpin yang mampu menjalin hubungan baik dengan karyawannya.

Berikut ini penilaian kepemimpinan yang dilakukan pada tahun 2017 yang ditunjukan pada tabel berikut ini : 
Tabel 1.1

Penilaian Kepemimpinan Bawaslu Kota Administrasi Jakarta Selatan Tahun 2017

\begin{tabular}{|c|c|c|c|c|c|}
\hline \multirow[t]{12}{*}{1} & \multicolumn{4}{|c|}{ UNSUR YANG DINILAI } & \multirow[b]{2}{*}{ Jumlah } \\
\hline & \multicolumn{2}{|c|}{ a. Sasaran Penilaian Kepemimpinan } & \multicolumn{2}{|c|}{ Nilai } & \\
\hline & Kepemimpinan & 1. Leadership & 61 & (Cukup) & 61 \\
\hline & & 2. Integritas & 70 & (Cukup) & 70 \\
\hline & & $\begin{array}{l}\text { 3. Kemampuan mengambil } \\
\text { keputusan }\end{array}$ & 50 & (Buruk) & 50 \\
\hline & & 4. Kemampuan komunikasi & 60 & (Sedang) & 60 \\
\hline & & $\begin{array}{l}\text { 5. Kemampuan mengendalikan } \\
\text { bawahan }\end{array}$ & 55 & (Sedang) & 55 \\
\hline & & 6. Kerjasama & 50 & (Buruk) & 50 \\
\hline & & Jumlah & 346 & & 346 \\
\hline & & Nilai rata-rata & 57.67 & $100 \%$ & 57.67 \\
\hline & & & & Sedang & \\
\hline & & Nilai Kepemimpinan & 61.38 & $60 \%$ & 36.83 \\
\hline & \multicolumn{5}{|c|}{ Kriteria: $<=50($ Buruk $),<=60($ Sedang $),<=70($ Cukup) $,<=90($ Baik $),<=99$ (Sangat Baik) } \\
\hline & & Nilai Kepemimpinan & & & Sedang \\
\hline
\end{tabular}

Sumber : Bawaslu Kota Administrasi Jakarta Selatan

Dari tabel 1.1 di atas, menunjukkan bahwa penilaian dari unsur kepemimpinan nilai presentasenya sangat beragam. Kemampuan mengambil keputusan dan hubungan kerja nilainya sangat buruk yaitu hanya 50\%. Untuk kemampuan komunikasi dan kemampuan mengendalikan bawahan nilainya sedang sedangkan leadership, integritas, kerjasama nilainya cukup.

Dari hasil tersebut semua item penilaian tidak ada yang mencapai kategori sangat baik, ini artinya kepemimpinan yang ada harus dievaluasi guna dapat bekerja dengan lebih baik. Sehingga menumbuhkan komitmen dalam lembaga dari diri karyawan. Sehingga pemimpin dapat meningkatkan kinerja karyawan agar lebih efektif dan efisien. Kepemimpinan sangat berperan besar dalam memberikan kualitas dan kuantitas kerja karyawan untuk mencapai suatu target maka pemimpin harus mampu memberikan motivasi dan support terhadap kinerja karyawan yang semakin menurun atas apa yang dikerjakan karyawan.

Permasalahan yang muncul dalam aspek kinerja tersebut yakni tidak terselesaikan target laporan bawaslu kota adminitrasi Jakarta selatan pada setiap tahunya karna 


\section{JURNAL ILMIAH MIMBAR DEMOKRASI}

84

mempengaruhi kepemimpinan yang belum sesuai standar.

Kinerja adalah hasil atau tingkat keberhasilan seseorang secara keseluruhan slama periode tertentu dalam melaksanakan tugas. (Amstrong dan Baroon, 1998:15) dalam Irham Fahmi: 2016 mengatakan "kinerja merupakan hasil pekerjaan yang mempunyai hubungan kuat dengan tujuan strategis organisasi, kepuasan konsumen dan memberikan kontribusi ekonomi”.

Table 1.2

Penilaian Kinerja Karyawan Bawaslu Kota Administrasi Jakarta Selatan

\begin{tabular}{|c|l|c|c|}
\hline No. & \multicolumn{1}{|c|}{ Kinerja Karyawan } & Nilai & Bobot Standar \\
\hline 1. & Kualitas Hasil Kerja & $15 \%$ & $20 \%$ \\
\hline 2. & Kuantitas Hasil Kerja & $12 \%$ & $15 \%$ \\
\hline 3. & Kemandirian Karyawan & $7 \%$ & $10 \%$ \\
\hline 4. & Kedisiplinan Karyawan & $5 \%$ & $10 \%$ \\
\hline 5. & Efektifitas \& Efisiensi Kerja & $7 \%$ & $10 \%$ \\
\hline 6. & Integritas \& Tanggung Jawab & $3 \%$ & $5 \%$ \\
\hline 7. & Pengembangan Diri & $3 \%$ & $5 \%$ \\
\hline 8. & Pengetahuan \& Keahlian Teknis & $8 \%$ & $10 \%$ \\
\hline 9. & Kerjasama & $7 \%$ & $10 \%$ \\
\hline 10. & Kemampuan Komunikasi & $3 \%$ & $5 \%$ \\
\hline \multicolumn{2}{r|}{ TOTAL } & $70 \%$ & $100 \%$ \\
\hline
\end{tabular}

\section{Sumber: Bawaslu Kota Administrasi Jakarta Selatan}

Berdasarkan pada table 1.2 bahwa kondisi kinerja karyawan Bawaslu Kota Administrasi Jakarta Selatan dapat dikatakan masih kurang baik. Hal ini dapat dilihat dari beberapa hal yang belum optimal seperti kuantitas hasil kerja dan kedisiplinan karyawan. Kuantitas hasil kerja karyawan Bawaslu Kota Administrasi Jakarta Selatan dikatakan belum memenuhi syarat dikarnakan pembagian tugas yang dilakukan terhadap karyawan masih belum merata. Hal ini terjadi karna kepemimpinan yang belum sesuai standar operasional. Sehingga mempengaruhi kinerja karyawannya, oleh karna itu berdasarkan data yang diambil secara kuantitas maka peneliti dapat menyimpulkan bahwa kuantitas menurun dan secara kualitas kinerja keryawan bermasalah dapat dilihat dari adanya karyawan yang menunda pekerjaan sehingga slalu terjadi 
keterlambatan dalam penuntasan pekerjaan yang diberikan. Dan berdasarkan hasil pra survey, tingkat kehadiran karyawan ditempat kerja masih kurang maksimal ditunjukan dengan kurangnya disiplin waktu dalam bekerja seperti masih adanya karyawan yang terlambat masuk kerja, pulang kerja lebih awal dari jam kerja. Berdasarkan uraian diatas peneliti mengambil kesimpulan bahwa masalah yang timbul ialah kepemimpinan yang ditunjukkan BAWASLU Kota Administrasi Jakarta Selatan yang sangat mempengaruhi kinerja karyawan sehingga berdampak kurang maksimalnya kinerja karyawan. Sehubungan dengan hal itu maka penulis tertarik untuk mengadakan penelitian lebih jauh terhadap Kemimpinan dengan Kinerja Karyawan Bawaslu Kota Administrasi Jakarta Selatan.

Dengan judul penelitian "Pengaruh Kepemimpinan Terhadap Kinerja Karyawan Bawaslu Kota Administrasi Jakarta Selatan".

\section{B. Rumusan Masalah}

Berdasarkan latar belakang masalah, identifikasi masalah dan pembatasan masalah, maka penulis merumuskan masalah sebagai berikut :

1. Bagaimana Kepemimpinan Bawaslu Kota Administrasi Jakarta Selatan?

2. Bagaimana Kinerja Karyawan Bawaslu Kota Administrasi Jakarta Selatan?

3. Bagaimana Pengaruh Kepemimpinan Terhadap Kinerja Karyawan Bawaslu Kota Administrasi Jakarta Selatan?

\section{Tujuan dan Manfaat Penelitian}

\section{Tujuan penelitian}

Adapun tujuan dari melakukan penelitian ini adalah :

a. Untuk mengetahui kepemimpinan pada

Bawaslu Kota Administrasi Jakarta Selatan.

b. Untuk mengetahui kinerja karyawan pada Bawaslu Kota Administrasi Jakarta Selatan.

c. Untuk mengetahui seberapa besar pengaruh kepemimpinan terhadap kinerja karyawan pada Bawaslu Kota Administrasi Jakarta Selatan. 


\section{Manfaat Penelitian}

Adapun manfaat penelitian yang akan dicapai antara lain sebagai berikut :

a. Manfaat Teoritis

1) Bagi Peneliti atau penulis

Untuk bias lebih memahami

permasalahan tentang sumber daya manusia yang telah dipelajari selama ini, serta menambah wawasan dan pengetahuan dan menanmbah pengalaman hidup bagaimana menjadi seorang pemimpin.

2) Bagi Akademis

Hasil penelitian mengenai pengaruh kepemimpinan terhadap kinerja karyawan ini diharapkan mampu juga dijadikan sebagai bahan masukan untuk mahasiswa dan mahasiswi lainnya, dan diharapkan dapat bermanfaat bagi semua rekan-rekan mahasiswa manajemen sumber daya manusia.

b. Manfaat Praktis

1) Bagi Perusahaan Melalui penelitian ini diharapkan dapat memberikan ide atau masukan untuk bahan pertimbangan dan evaluasi untuk mendapatkan kinerja yang lebih baik dimasa mendatang. Dengan mengetahui berapa besar pengaruh kepemimpinan

terhadap kinerja karyawan Bawaslu Kota Administrasi Jakarta Selatan berarti lembaga dapat menentukan

kepemimpinan apa yang diterapkan untuk meningkatkan kinerja karyawan sesuai permasalahan yang dihadapi lembaganya.

\section{KAJIAN TEORI}

\section{Kinerja}

Kinerja merupakan tingkat pencapaian hasil atas pelaksanaan 
tugas tertentu dalam konteks pengembangan sumber daya manusia kinerja seorang karyawan dalam sebuah perusahaan sangat dibutuhkan untuk mencapai prestasi kerja bagi karyawan itu sendiri dan juga untuk kebrhasilan perusahaan.

Menurut Soedarmayanti (2011:260) kinerja adalah hasil kerja yang dapat dicapai oleh seseorang atau sekelompok dalam organisasi, sesuai dengan wewenang dan tanggung jawab masing-masing dalam upaya mencapai tujuan organisasi bersangkutan secara legal, tidak melanggar hukum, sesuai moral dan etika.

Menurut Mangkunegara (2011:67) kinerja (prestasi kerja) adalah hasil kerja secara kualitas dan kuantitas yang dicapai oleh seseorang karyawan dalam melaksanakan tugasnya sesuai dengan tanggung jawab yang diberikan kepadanya. Menurut Wibowo (2013:4) mendefinisikan kinerja adalah merupakan implementasi dari rencanan yang telah disusun tersebut. Implementasi kerja dilakukan oleh sumber daya manusia yang memiliki kemampuan, kompetensi, motivasi dan kepentingan

Faktor-faktor yang dapat mampengaruhi pencapaian kinerja adalah factor kemampuan (ability) dan factor motivasi (motivation). Menurut Sutrisno (2013:151) factor-faktor yang dapat mempengarugi kinerja adalah:

a. Faktor Kemampuan, secara psikologis kemampuan terdiri dari kemampuan potensi (IQ) dan kemampuan realita, artinya karyawan yang memiliki IQ rata-rata (IQ 110-120) dengan memadai untuk jabatan dan terampil dalam mengerjakan pekerjaan sehari-hari, maka ia akan lebih mudah mencapai kinerja yang diharapkan oleh karena itu karyawan perlu ditetapkan pada pekerjaan yang sesuai dengan keahliannya.

b. Faktor kepemimpinan, meliputi aspek kualitas manajer dan team leader dalam memberikan semangat, arahan dan dukungan kerja kepada karyawan. 
c. Faktor tim, meliputi kualitas dan dukungan semangat yang diberikan oleh rekan kerja dalam satu tim, kepercayaan terhadap sesame anggota tim, kekompakan dan keeratan anggota tim.

d. Faktor system, meliputi system kerja, fasilitas kerja atau infrastruktur yang diberikan oleh organisasi, proses organisasi dan kultur kinerja dalam organisasi.

e. Faktor situasional, meliputi rekanan dan perubahan lingkungan eksternal dan internal.

f. Konflik, meliputi dalam diri individu / konflik peran, konflik antar individu, konflik antar kelompok atau organisasi.

\section{Kepemimpinan}

Setiap organisasi apapun jenisnya pasti memerlukan dan memiliki seorang pemimpin tertinggi (pimpinan puncak) dan manajer tertinggi (top manager) yang harus menjalankan kegiatan kepemimpinan (leadership) dan Manajemen bagi keseluruhan organisasi sebagai satu kesatuan.
Semua para pemimpin dapat mempengaruhi moral, kepuasan kerja, kualitas kehidupan, kerja, dan terutama tingkat prestasi suatu organisasi. Untuk mencapai semua itu seorang pemimpin harus mempunyai kemampuan dan keterampilan kepemimpinan dalam melakukan pengarahan kepada bawahannya untuk mencapai tujuan organisasi. Berikut ini define kepemimpinan menurut para ahli diantaranya :

Menurut Asep Saefullah dan Ahmad Rusdiana (2016:64) kepemimpinan merupakan salah satu unsur penentu keberhasilan organisasi, terutama dalam menuju perubahan. Menurut Hani Handoko (2012:294) kepemimpinan merupakan kemampuan yang dimiliki seseorang untuk mempengaruhi orang lain agar bekerja mencapai tujuan dan sasaran.

\section{Menurut Hasibuan} (2011:170) kepemimpinan adalah sebuah cara seseorang pemimpin yang mempengaruhi perilaku bawahan agar mampu bekerja sama dengan bekerja secara efektif dan efisien untuk mencapai tujuan organisasi. Dari 
berbagai pendapat dapat di sintesiskan bahwa kepemimpinan merupakan suatu cara seseorang pemimpin dalam usahanya untuk mempengaruhi dan mengarahkan bawahannya agar mau melaksanakan tugasnya dengan bekerja sama untuk mencapai tujuan organisasi.

Setiap organisasi memiliki target perubahan yang berbeda sesuai dengan kebutuhan dan factor dominan yang mendorong perubahan. Menurut Asep Saefullah dan ahmad Rusdiana (2016:69) dalam bukunya mengatakan perubahan organisasi merupakan suatu tindakan yang dilakukan terhadap unsur-unsur dalam suatu organisasi untuk meningkatkan efektivitas organisasi menuju arah yang lebih baik dari pada sebelumnya. Dalam bukunya Asep Saefullah dan Ahmad Rusdiana (2016:70) terdapat 7 unsur yang esensial dalam konsep kepemimpinan perubahan yaitu :

a. Pemimpin (leader)

Pemimpin adalah seorang pribadi yang memiliki kecakapan dan kelebihan sehingga mampu mempengaruhi orang lain untuk bersam-sama melakukan aktifitas tertentu untuk mencapai tujuan.

b. Pengaruh (influence)

Pengaruh merupakan daya atau kekuatan yang timbul dari sesuatu, baik orang yang maupun benda serta segala sesuatu yang ada di alam sehingga mempengaruhi semua yang ada di sekitarnya.

c. Pengikut (follower)

Seseorang dikatakan memimpin suatu organisasi karena ada yang dipimpin, yaitu pengikut. Pemimpin yang berhasil dalam suatu organisasi adalah pemimpin berkarakter kuat dengan pengikut yang efektif.

d. Maksud (Intention)

Itensi adalah niat atau keinginan yang timbul pada individu untuk melakukan sesuatu. Keinginan karyawan untuk berpindah mengacu pada hasil evaluasi individu mengenai kelanjutan hubungan dengan organisasi yang belum diwujudkan dalam tindakan pasti meninggalkan organisasi. 
e. Tujuan Bersama (Shared Purpose)

Pemimpin memastikan kelompok berbagi akal sehat komitmen bahwa orangorang dapat melihat yang relevan dengan kelompok dan individu.

f. Perubahan (Chage)

Manusia slalu mendambakan perubahan kearah yang lebih baik. Perubahan secara nyata dan masif hanya dapat dilakukan oleh pemimpin. Hanya pemimpin yang memiliki konsep dan arah yang jelas tentang yang mampu mewujudkan.

g. Tanggung Jawab Pribadi (Personal Responbility)

Pemimpin bertanggung jawab terhadap performa diri sendiri dan upaya pengembangan kearah yang lebih berkualitas. Pengelolaan diri sendiri supaya tampil dengan performa prima dalam pelaksanaan tugas pokok sehari-hari

\section{METODE PENELITIAN}

Penelitian ini dilakukan di Bawaslu Kota Administrasi Jakarta Selatan.
Berdasarkan permasalahan dalam penelitian ini, maka penulis memberikan batasan masalah dengan lingkup penelitian mengenai “ Pengaruh Kepemimpinan Terhadap Kinerja Karyawan Pada Bawalu Kota Administrasi Jakarta Selatan"

Penelitian ini dilakukan pada karyawan Bawaslu Kota Administrasi Jakarta Selatan yang beralamatkan di Jalan Warung Jati Barat No. 11, Kalibata, Pancoran, Jakarta Selatan 12740 Penelitian dilakukan dengan tujuan untuk mengungkapkan permasalahan yang diteliti. Dalam penelitian ini mengenai Pengaruh Kepemimpinan terhadap Kinerja Karyawan Bawaslu Kota Administrasi Jakarta Selatan menggunakan metode asosiatif pendekatan kuantitatif.

Metode penelitian yang penulis gunakan dalam penelitian ini adalah penelitian asosiatif dengan pendekatan kuantitatif. Metode penelitian kuantitatif digunakan untuk mendapatkan data dari tempat tertentu yang alamiah (bukan bantuan), tetapi peneliti melakukan perlakuan dalam pengumpulan data, misalnya dengan menyebarkan kuesioner dan sebagainya. 
HASIL DAN PEMBAHASAN

\section{Analisis Data Penelitian}

Penelitian dilakukan baik secara pengamatan maupun penyebaran

kuesioner kepada 96 responden sebagai sampel untuk mengukur tingkat variabel kepemimpinan dan variabel kinerja karyawan Bawaslu Kota Administrasi Jakarta Selatan dengan skor yang diberikan adalah sebagai berikut :

Tabel 4.5

Skor Tiap Butir Jawaban Variabel

\begin{tabular}{|c|c|}
\hline Pilihan Jawaban & Peringkat Nilai (Skor) \\
\hline SS (Sangat Setuju) & 5 \\
\hline S (Setuju) & 4 \\
\hline R(Ragu-Ragu) & 3 \\
\hline TS(Tidak Setuju) & 2 \\
\hline STS ( Sangat Tidak Setuju ) & 1 \\
\hline
\end{tabular}

a. Hasil Analisis Data

Responden Kepemimpinan

Hasil jawaban dari 96

responden mengenai

kepemimpinan yang terjadi

dari 10 pernyataan jawaban tersebut kemudian di analisi dengan menggunakan presentase jawaban semuanya itu tertuang dan di jelaskan dalam table sebagai berikat :

Tabel 4.6

Deskripsi Variabel Kepemimpinan (X)

\begin{tabular}{|c|c|c|c|c|c|c|c|c|c|c|c|}
\hline No & Indikator & Pernyataan & SS & $\mathbf{S}$ & $\begin{array}{l}\mathbf{K} \\
\mathbf{S}\end{array}$ & $\begin{array}{l}\mathbf{T} \\
\mathbf{S}\end{array}$ & $\begin{array}{l}\text { ST } \\
\text { S }\end{array}$ & $\begin{array}{c}\Sigma \\
\operatorname{Res} \\
\mathbf{p}\end{array}$ & $\begin{array}{c}\text { Sko } \\
\text { r }\end{array}$ & $\begin{array}{c}\text { Rat } \\
\text { a- } \\
\text { rata }\end{array}$ & $\begin{array}{c}\text { Kriter } \\
\text { ia }\end{array}$ \\
\hline 1 & & $\begin{array}{c}\text { Pemimpin } \\
\text { mengutamak } \\
\text { an etika } \\
\text { dalam } \\
\text { bekerja }\end{array}$ & 14 & 52 & 22 & 8 & 0 & 96 & 360 & 3,75 & Baik \\
\hline 2 & $\begin{array}{c}\text { Keteladan } \\
\text { an }\end{array}$ & $\begin{array}{l}\text { Pemimpin } \\
\text { memberikan } \\
\text { keteladanan } \\
\text { yang baik } \\
\text { sebagai } \\
\text { seorang } \\
\text { pemimpin }\end{array}$ & 16 & 70 & 9 & 1 & 0 & 96 & 389 & 4.05 & Baik \\
\hline 3 & $\begin{array}{c}\text { Kewibawa } \\
\text { an }\end{array}$ & $\begin{array}{c}\text { Pemimpin } \\
\text { menggunaka }\end{array}$ & 18 & 67 & 10 & 1 & 0 & 96 & 390 & 4,06 & Baik \\
\hline
\end{tabular}




\section{JURNAL ILMIAH MIMBAR DEMOKRASI}

92

VOLUME 19, NOMOR 1, OKTOBER 2019

\begin{tabular}{|c|c|c|c|c|c|c|c|c|c|c|c|}
\hline No & Indikator & Pernyataan & SS & $\mathbf{S}$ & $\begin{array}{l}\mathbf{K} \\
\mathbf{S}\end{array}$ & $\begin{array}{l}\mathbf{T} \\
\mathbf{S}\end{array}$ & $\begin{array}{l}\text { ST } \\
\text { S }\end{array}$ & $\begin{array}{c}\Sigma \\
\operatorname{Res} \\
\mathbf{p} \\
\end{array}$ & $\begin{array}{c}\text { Sko } \\
\text { r }\end{array}$ & $\begin{array}{c}\text { Rat } \\
\text { a- } \\
\text { rata } \\
\end{array}$ & $\begin{array}{c}\text { Kriter } \\
\text { ia }\end{array}$ \\
\hline & & $\begin{array}{c}\mathrm{n} \text { bahasa } \\
\text { yang santun }\end{array}$ & & & & & & & & & \\
\hline 4 & & $\begin{array}{l}\text { Pemimpin } \\
\text { berpakaian } \\
\text { rapih dan } \\
\text { sopan }\end{array}$ & 13 & 68 & 14 & 1 & 0 & 96 & 379 & 3,95 & Baik \\
\hline 5 & $\begin{array}{l}\text { Pendelega } \\
\text { sian }\end{array}$ & $\begin{array}{c}\text { Pemimpin } \\
\text { mampu } \\
\text { mendelegasi } \\
\text { kan } \\
\text { wewenang } \\
\text { kepada } \\
\text { bawahannya } \\
\text { secara } \\
\text { efektif }\end{array}$ & 12 & 69 & 13 & 2 & 0 & 96 & 379 & 3,95 & Baik \\
\hline 6 & Tugas & $\begin{array}{l}\text { Pemimpin } \\
\text { memberikan } \\
\text { perintah dan } \\
\text { tugas sesuai } \\
\text { dengan } \\
\text { prosedur } \\
\text { yang } \\
\text { ditetapkan }\end{array}$ & 9 & 58 & 29 & 0 & 0 & 96 & 364 & 3,79 & Baik \\
\hline 7 & $\begin{array}{l}\text { Pengambil } \\
\text { an }\end{array}$ & $\begin{array}{l}\text { Pemimpin } \\
\text { bertindak } \\
\text { tegas dalam } \\
\text { mengambil } \\
\text { keputusan }\end{array}$ & 4 & 64 & 24 & 4 & 0 & 96 & 356 & 3,71 & Baik \\
\hline 8 & Keputusan & $\begin{array}{l}\text { Pemimpin } \\
\text { mengambil } \\
\text { keputusan } \\
\text { dengan tegas }\end{array}$ & 13 & 75 & 8 & 0 & 0 & 96 & 389 & 4,05 & Baik \\
\hline 9 & Motivasi & $\begin{array}{l}\text { Pemimpin } \\
\text { memberikan } \\
\text { motivasi dan } \\
\text { arahan } \\
\text { dalam } \\
\text { bekerja }\end{array}$ & 22 & 67 & 5 & 2 & 0 & 96 & 397 & 4,13 & Baik \\
\hline 10 & & $\begin{array}{l}\text { Pemimpin } \\
\text { memberikan } \\
\text { reward pada } \\
\text { karyawan }\end{array}$ & 12 & 38 & 37 & 9 & 0 & 96 & 341 & 3,55 & Baik \\
\hline \multicolumn{3}{|c|}{ Total } & $\begin{array}{c}13 \\
3\end{array}$ & $\begin{array}{c}62 \\
8\end{array}$ & $\begin{array}{c}17 \\
1\end{array}$ & 28 & 0 & 960 & $\begin{array}{c}374 \\
4\end{array}$ & 3,9 & Baik \\
\hline \multicolumn{3}{|c|}{ Peresentase } & $14 \%$ & $55 \%$ & $18 \%$ & $3 \%$ & $0 \%$ & $\begin{array}{c}100 \\
\%\end{array}$ & & & \\
\hline
\end{tabular}

Sumber : Data olahan kuesioner 2018 


$$
\text { Jumlah }
$$
hasil

pernyataan $=\mathrm{SS}+\mathrm{S}+\mathrm{R}+\mathrm{TS}$

+ STS yaitu $133+628+171$

$+28=960$ dan selanjutnya

berdasarkan data hasil

pengolahan yang telah

dilakukan diatas maka dapat

ditentukan hasil presentase

dari tiap instrumen

pernyataan dikalikan $100 \%$

seperti yang ditunjukan

sebagai berikut :

$$
\begin{aligned}
\text { Jawaban SS }= & \frac{133}{960} \times 100 \% \\
& =14 \%
\end{aligned}
$$

Jawaban $S=\frac{628}{960} \times 100 \%$

$$
=65 \%
$$

Jawaban $\mathrm{R}=\frac{171}{960} \times 100 \%$

$$
=18 \%
$$

Jawaban TS $=\frac{28}{960} \times 100 \%$

$$
=3 \%
$$

Jawaban STS $=\frac{0}{960} \times 100 \%=0 \%$

Berdasarkan data

diatas dapat dilihat seluruh responden pada karyawan pada Bawaslu Kota

Administrasi Jakarta Selatan yang berjumlah 96 orang menjawab "sangat setuju" sebanyak 133 atau 14\%, yang menjawab "setuju" sebanyak 628 atau $65 \%$, jawaban "ragu-ragu" sebanyak 171 atau $18 \%$, jawaban "tidak setuju" sebanyak 28 atau $3 \%$ dan jawaban "sangat tidak setuju" 0 atau $0 \%$.

\section{b. Hasil Analisi Data}

\section{Responden \\ Kinerja}

\section{Karyawan (Y)}

Hasil jawaban dari 96 responden mengenai Kinerja Karyawan yang terjadi dari 10 pernyataan jawaban tersebut kemudian di analisi dengan menggunakan presentase jawaban semuanya itu tertuang dan di jelaskan dalam table sebagai berikut :

\section{Deskripsi Variabel Kinerja (Y)}

\begin{tabular}{|l|l|l|l|l|l|l|l|l|l|l|l|}
\hline No & $\begin{array}{c}\text { Indika } \\
\text { tor }\end{array}$ & Pertanyaan & SS & S & KS & $\begin{array}{c}\text { T } \\
\text { S }\end{array}$ & $\begin{array}{c}\text { ST } \\
\text { S }\end{array}$ & $\begin{array}{c}\mathbf{2} \\
\text { Res } \\
\mathbf{p}\end{array}$ & $\begin{array}{c}\text { Sko } \\
\mathbf{r}\end{array}$ & $\begin{array}{c}\text { Rata } \\
- \\
\text { rata }\end{array}$ & $\begin{array}{c}\text { Kriteri } \\
\mathbf{a}\end{array}$ \\
\hline 1 & $\begin{array}{c}\text { Kualita } \\
\text { s Kerja }\end{array}$ & $\begin{array}{l}\text { Karyawan } \\
\text { mengerjakan }\end{array}$ & 18 & 43 & 34 & 1 & 0 & 96 & 364 & 3,79 & Baik \\
\hline
\end{tabular}


JURNAL ILMIAH MIMBAR DEMOKRASI

94

VOLUME 19, NOMOR 1, OKTOBER 2019

\begin{tabular}{|c|c|c|c|c|c|c|c|c|c|c|c|}
\hline No & $\begin{array}{c}\text { Indika } \\
\text { tor }\end{array}$ & Pertanyaan & SS & $\mathbf{S}$ & $\mathbf{K S}$ & $\begin{array}{l}\mathbf{T} \\
\mathbf{S}\end{array}$ & $\begin{array}{l}\text { ST } \\
\text { S }\end{array}$ & $\begin{array}{c}\Sigma \\
\operatorname{Res} \\
\mathbf{p}\end{array}$ & $\begin{array}{c}\text { Sko } \\
\mathbf{r}\end{array}$ & $\begin{array}{c}\text { Rata } \\
- \\
\text { rata }\end{array}$ & $\begin{array}{l}\text { Kriteri } \\
\quad \mathbf{a}\end{array}$ \\
\hline & & $\begin{array}{l}\text { tugas sesuai } \\
\text { dengan SOP } \\
\end{array}$ & & & & & & & & & \\
\hline 2 & & $\begin{array}{l}\text { Karyawan } \\
\text { melakukan } \\
\text { pekerjaan } \\
\text { dengan teliti } \\
\text { untuk } \\
\text { mendapat } \\
\text { hasil yang } \\
\text { memuaskan }\end{array}$ & 20 & 74 & 1 & 1 & 0 & 96 & 399 & 4,16 & Baik \\
\hline 3 & Kuantit & $\begin{array}{l}\text { Karyawan } \\
\text { mampu } \\
\text { menyelesaika } \\
\text { n tugas sesuai } \\
\text { waktu yang } \\
\text { ditentukan }\end{array}$ & 19 & 53 & 19 & 5 & 0 & 96 & 374 & 3,89 & Baik \\
\hline 4 & $\begin{array}{c}\text { as } \\
\text { Kerja }\end{array}$ & $\begin{array}{l}\text { Karyawan } \\
\text { melakukan } \\
\text { lembur kerja } \\
\text { untuk } \\
\text { menyelesaika } \\
\text { n tugas }\end{array}$ & 25 & 56 & 9 & 6 & 0 & 96 & 388 & 4,04 & \\
\hline 5 & & $\begin{array}{l}\text { Karyawan } \\
\text { bertanggung } \\
\text { jawab penuh } \\
\text { terhadap } \\
\text { pekerjaan }\end{array}$ & 43 & 49 & 4 & 0 & 0 & 96 & 423 & 4,40 & $\begin{array}{l}\text { Sangat } \\
\text { Baik }\end{array}$ \\
\hline 6 & $\begin{array}{c}\text { I anggu } \\
\text { ng } \\
\text { Jawab }\end{array}$ & $\begin{array}{l}\text { Karyawan } \\
\text { menyelesaika } \\
\mathrm{n} \text { tugas yang } \\
\text { diberikan } \\
\text { atasan/pemim } \\
\text { pin dengan } \\
\text { baik }\end{array}$ & 20 & 57 & 18 & 1 & 0 & 96 & 384 & 4 & Baik \\
\hline 7 & $\begin{array}{l}\text { Kerja } \\
\text { Sama }\end{array}$ & $\begin{array}{l}\text { Karyawan } \\
\text { memiliki kerja } \\
\text { sama yang } \\
\text { baik dalam } \\
\text { perusahaan } \\
\text { baik kepada } \\
\text { teman } \\
\text { maupun } \\
\text { atasan } \\
\end{array}$ & 21 & 70 & 4 & 1 & 0 & 96 & 399 & 4,15 & Baik \\
\hline 8 & & $\begin{array}{l}\text { Keryawan } \\
\text { mampu } \\
\text { menerima } \\
\text { informasi dari } \\
\end{array}$ & 6 & 69 & 19 & 2 & 0 & 96 & 367 & 3,82 & Baik \\
\hline
\end{tabular}




\begin{tabular}{|c|c|c|c|c|c|c|c|c|c|c|c|}
\hline No & $\begin{array}{c}\text { Indika } \\
\text { tor }\end{array}$ & Pertanyaan & SS & $\mathbf{S}$ & KS & $\begin{array}{l}\mathbf{T} \\
\mathbf{S}\end{array}$ & $\begin{array}{c}\text { ST } \\
\text { S }\end{array}$ & $\begin{array}{c}\Sigma \\
\operatorname{Res} \\
\mathbf{p}\end{array}$ & $\begin{array}{c}\text { Sko } \\
\mathbf{r}\end{array}$ & $\begin{array}{c}\text { Rata } \\
- \\
\text { rata }\end{array}$ & $\begin{array}{c}\text { Kriteri } \\
\quad \mathbf{a}\end{array}$ \\
\hline & & $\begin{array}{l}\text { atasan } \\
\text { maupun dari } \\
\text { bawahan } \\
\text { dengan baik }\end{array}$ & & & & & & & & & \\
\hline 9 & \multirow{2}{*}{$\begin{array}{c}\text { Kejujur } \\
\text { an }\end{array}$} & $\begin{array}{l}\text { Karyawan } \\
\text { slalu memiliki } \\
\text { kejujuran } \\
\text { terhadap diri } \\
\text { sendiri, teman } \\
\text { dan pimpinan }\end{array}$ & 16 & 73 & 7 & 0 & 0 & 96 & 393 & 4,09 & Baik \\
\hline 10 & & $\begin{array}{l}\text { Karyawan } \\
\text { mampu } \\
\text { menjaga } \\
\text { tanggung } \\
\text { jawab dengan } \\
\text { tuganya }\end{array}$ & 31 & 60 & 5 & 0 & 0 & 96 & 410 & 4,27 & $\begin{array}{l}\text { Sanat } \\
\text { Baik }\end{array}$ \\
\hline \multicolumn{3}{|c|}{ Total } & $\begin{array}{c}21 \\
9\end{array}$ & $\begin{array}{c}60 \\
4\end{array}$ & $\begin{array}{c}12 \\
0\end{array}$ & 17 & 0 & 960 & $\begin{array}{c}390 \\
1\end{array}$ & 4,06 & Baik \\
\hline \multicolumn{3}{|c|}{ Persenatse } & $\begin{array}{l}23 \\
\%\end{array}$ & $\begin{array}{l}63 \\
\%\end{array}$ & $\begin{array}{l}13 \\
\%\end{array}$ & $\begin{array}{l}2 \\
\%\end{array}$ & 0 & $\begin{array}{c}100 \\
\%\end{array}$ & & & \\
\hline
\end{tabular}

Sumber : Data olahan kuesioner 2018

Jumlah hasil

pernyataan $=\mathrm{SS}+\mathrm{S}+\mathrm{R}+\mathrm{TS}$

+ STS yaitu $219+604+120$

$+17=960$ dan selanjutnya

berdasarkan data hasil

pengolahan yang telah

dilakukan diatas maka dapat

ditentukan hasil presentase

dari tiap instrumen

pernyataan dikalikan $100 \%$

seperti yang ditunjukan

sebagai berikut :

$$
\begin{aligned}
\text { Jawaban SS }= & \frac{219}{960} \times 100 \% \\
& =23 \%
\end{aligned}
$$

Jawaban $S=\frac{604}{960} \times 100 \%$

$$
=63 \%
$$

Jawaban $\mathrm{R}=\frac{120}{960} \times 100 \%$

$$
=13 \%
$$

Jawaban TS $=\frac{17}{960} \times 100 \%$

$$
=2 \%
$$

Jawaban STS $=\frac{0}{960} \times 100 \%=0 \%$

Berdasarkan data diatas dapat dilihat seluruh responden pada karyawan pada Bawaslu Kota Administrasi Jakarta Selatan yang berjumlah 96 orang menjawab "sangat setuju" sebanyak 219 atau 23\%, yang menjawab "setuju" sebanyak 604 atau 63\%, jawaban 
“ragu-ragu” sebanyak 120 atau 13\%, jawaban "tidak setuju" sebanyak 17 atau $2 \%$ dan jawaban "sangat tidak setuju" 0 atau $0 \%$. Ulasan diatas adalah deskripsi data variabel kinerja Karyawan berdasarkan skala dengan data keseluruhan.

\section{PENUTUP}

Penutup merupakan bagian akhir dari keseluruhan naskah yang meliputi: kesimpulan dan saran (jika ada).

\section{A. Kesimpulan}

Berdasarkan hasil penelitian dan analisis data yang telah dilakukan dan dipaparkan dalam penelitian ini mengenai Pengaruh Kepemimpinan Terhadap Kinerja Karyawan Pada Bawaslu Kota Administrasi Jakarta Selatan, maka penulis dapat menyimpulkan sebagai berikut :

1. Kepemimpinan di bawaslu kota administrasi jakarta selatan berdasarkan pernyataan responden sebanyak 96 responden, didapat responden secara keseluruhan sudah dalam kriteria baik. Hal ini terbukti pada tabel 4.6 deskripsi variabel kepemimpinan yang dinyatakan dalam rata-rata 3,9 dengan kriteria rentang 3,40-4,19 dalam kriteria baik.

2. Kinerja karyawan yang terdapat pada Bawaslu Kota Administrasi Jakarta Selatan berdasarkan pernyataan reponden sebanyak 96 responden, didapat responden secara keseluruhan sudah dalam kriteria baik. Hal ini terbukti pada tabel 4.7 deskripsi variabel kinerja karyawan yang dinyatakan bahwa dalam rata-rata 4,06 dengan kriteria rentang 3,404,19 dalam kriteria baik.

3. Pengaruh kepemimpinan terhadap kinerja karyawan bawaslu kota administrasi jakarta selatan berdasarkan hasil perhitungan model regresi yang diperoleh adalah $\mathrm{Y}=21,77+$ 0,484 X. Artinya konstanta sebesar 21,77 menyatakan bahwa tanpa kepemimpinan, kinerja karyawan tetap terbentuk sebesar 21,77. Variabel kepemimpinan berpengaruh positif terhadap kinerja dengan nilai koefisien sebesar 0,484. Artinya jika variabel kepemimpinan meningkat satu satuan, maka kinerja akan meningkat sebesar 0,484. Hasil perhitungan koefisien korelasi, maka diperoleh nilai $\mathbf{r}$ sebesar 0,468 
maka bila dilihat tabel interpretasi koefisien korelasi masuk pada interval $0,40-0,599$ dengan tingkat pengaruh sedang. Artinya bahwa terdapat hubungan yang sedang antara variabel $\mathrm{X}$ (Kepemimpinan) dengan variabel Y (Kinerja Karyawan). Hasil perhitungan nilai kontribusi determinasi $(\mathrm{KD})=21,90 \%$ artinya menunjukan bahwa kontribusi variabel $\mathrm{X}$ (Kepemimpinan) berpengaruh terhadap variabel $\mathrm{Y}$ (Kinerja Karyawan) yaitu sebesar 21,90\% sedangkan lebihnya yaitu $78,1 \%$ variabel Y (Kinerja Karyawan) dipengaruhi oleh faktor-faktor lain yang tidak diteliti penulis. Hasil perhitungan Uji Signifikasi didapat jika nilai $t_{\text {hitung }}$ sebesar $4,934>t_{\text {tabel }} 1,99$ yang sehingga $H_{0}$ ditolak dan $H_{a}$ diterima, artinya ada pengaruh yang positif dan signifikan antara kepemimpinan terhadap kinerja karyawan Bawaslu Kota Administrasi Jakarta Selatan.

\section{B. Saran}

Mempertimbangkan pada hasil penelitian ini, makan beberapa saran yang dapat peneliti sampaikan pada pihak perusahaan yaitu Bawaslu Kota
Administrasi Jakarta Selatan adalah sebagi berikut :

1. Disarankan pada Bawaslu Kota Administrasi Jakarta Selatan agar para pemimpin bisa memberi motivasi yang lebih besar kepada karyawan dengan memberikan reward kepada karyawan yang memiliki kinerja yang lebih baik, sehingga memacu semangat karyawan untuk menyelesaikan pekerjaannya.

2. Disarankan bagi para karyawan Bawaslu Kota Administrasi Jakarta Selatan untuk meningnkatkan kuantias kerja sehingga tanggung jawab pekerjaan yang telah diterima mampu diselesaikan tepat pada waktunya.

\section{DAFTAR PUSTAKA}

Abdullah, M. Ma'ruf. 2013. Manajemen dan Evaluasi Kinerja Karyawan. Aswaja Pressindo. Yogyakarta.

Bangun, Wilson. 2012. Manajemen Sumber Daya Manusia. Penerbit Erlangga. Bandung.

Hanafi, Mamduh. 2015. Manajemen. Penerbit Universitas Terbuka. Tangerang Selatan.

Iswanto, Yun. 2015. Manajemen Sumber Daya Manusia. Penerbit 
Universitas Terbuka. Tangerang Selatan.

Mangkunegara, A.A. Anwar Prabu. 2015. Manajemen Sumber Daya Manusia Perusahaan. Penerbit Remaja Rosdakarya. Bandung. 2011.

Perilaku dan Budaya Organisasi. Cetakan Ketiga. Penerbit Refika Aditama. Bandung.

Malayu S.P Hasibuan. 2011. Manajemen Sumber Daya Manusia. Bumi Aksara. Jakarta.

. 2013. Manajemen

Sumber Daya Manusia. Bumi Aksara. Jakarta.

2015. Manajemen

Sumber Daya Manusia. Bumi Aksara. Jakarta.

-. 2017. Manajemen Sumber Daya Manusia. Edisi Revisi. Bumi Aksara. Jakarta.

Suwanto. 2011. Asas-Asas Manajemen Sumber Daya Manusia. Penerbit Suci Press. Bandung.

Sutrisno, Edy. 2013. Manajemen Sumber Daya Manusia. Kencana. Jakarta.

Safroni, Ladzi. 2012. Manajemen dan Reformasi Pelayanan Publik dalam Konteks Birokrasi Indonesia. Aditya Media Publishing. Surabaya.

Soedarmayanti. 2013. Manajemen Sumber Daya Manusia. Cetakan Ke-6 Refika Aditama. Bandung. .2011. Manajemen Sumber Daya Manusia: Reformasi Birokrasi dan Manajemen
Pegawai Negeri Sipil. Cet. Ket-5. Refika Aditama. Bandung.

Sugiyono. 2010. Metode Penelitian Kuantitatif Kualitatif $R \& D$.

Alfabet. Bandung.

. 2012. Metode Penelitian Kuantitatif Kualitatif $R \& D$. Alfabet. Bandung.

. 2014. Metode Penelitian Kuantitatif Kualitatif $R \& D$. Alfabet. Bandung.

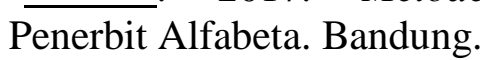

2017. Metode Penelitian.

T. Hani Handoko. 2012. Manajemen Personalia dan Sumber Daya Manusia, Jilid 2. Yogyakarta. BPFE Yogyakarta.

2013.Manajemen. Edisi Kedua Cetakan Kedua Puluh Lima. Penerbit BPFE. Yogyakarta.

Wibowo. 2013. Manajemen Kinerja. Edisi Kelima, Rajawali Pers. Jakarta.

.2016. Manajemen Kinerja. Edisi Kelima, Cetakan Ke-10 Raja Grafindo Persada. Jakarta.

Wirawan. 2014. Kepemimpinan: Teori, Psikologi, perilaku Organisasi, Aplikasi dan Penelitian, Ed. 1. Cet. @. Rajawali Pers. Jakarta. 